\title{
UN FRAGMENT D'ESCULTURA TROBAT A LA VIL•LA ROMANA DEL RAJOLAR (GANDIA, VALÈNCIA)
}

FERRAN ARASA I GIL

Dpt. de Prehistòria, Arqueologia i H ${ }^{\mathrm{a}}$ Antiga. Universitat de València. Ferran.Arasa@uv.es

El fragment d'escultura que presentem es trobà a la vil·la romana del Rajolar (Gandia, la Safor), en la campanya de 2006 dirigida per J. V. Escrivà i I. Sifres, als qui agraïsc la informació sobre l'excavació. La notícia fou mencionada per E. Moscardó (2008: 190) en un treball sobre el poblament rural d'època romana al sector $\mathrm{N}$ del territori de Dianium. Posteriorment, el director del $\mathrm{Mu}-$ seu Arqueològic de Gandia, J. Cardona, em va facilitar les primeres fotografies i l'estudi de la peça, que vaig poder efectuar en abril del 2016. La villa, una de les de major superfície de la comarca, presenta una àmplia cronologia que s'estén entre els ss. I i IV-V dE. El fragment escultòric, l'únic trobat en les excavacions d'aquesta vil·la, aparegué al sondeig C de la parcel·la B-2, que correspon a la pars fructuaria (fig. 1). Formava part del rebliment (UE 3014) d'un pou situat a la vora d'una canalització (UE 3020) que passa a prop del torcularium (fig. 2), juntament amb materials de construcció, en un context que pot datar-se en els ss. I-II (Escrivà i Sifres 2006: 157, fig. 79).

La peça és de marbre blanc de gra fi i no s'ha sotmés a cap neteja, per la qual cosa la seua superfície presenta una coloració terrosa. Les seues dimensions són 15,5cm d'altura, 14,5 cm d'amplària i 10 cm de grossària (fig. 3). Pertanyia a una figureta exempta de proporcions menors que el natural que representava un personatge masculí, del qual es conserven les cuixes, des dels genitals fins als genolls, que mostren un modelatge suau. En la part superior, la línia de fractura talla els genitals i dibuixa un plànol prou regular; i en la inferior davalla d'esquerra a dreta i és més irregular. En general està ben conservada, excepte algunes gratades i esvorancs moderns, i presenta un bon acabat, amb la superfície allisada. Les fractures de la part inferior són més recents que les de la superior i del costat dret, el que indica que es va trencar almenys en dos moments. La cama esquerra presenta un orifici de 4 $\mathrm{mm}$ de diàmetre i $6 \mathrm{~mm}$ de profunditat per a un pern, bé per a fixar-la per ser una peça a banda, bé per a unir-la després d'una hipotètica fractura. El pes del cos descansa en la cama dreta i té l'esquerra lleugerament doblada i avançada. Dels genitals se'n conserven els testicles, un poc danyat el dret. En l'extrem superior de la cuixa esquerra es veu l'inici del maluc i de la zona glútia.

En la part posterior es veu el mantell que cau verticalment fins a davall de les natges i resta exonerat per la zona central i el costat esquerre, on se separa de la cama 


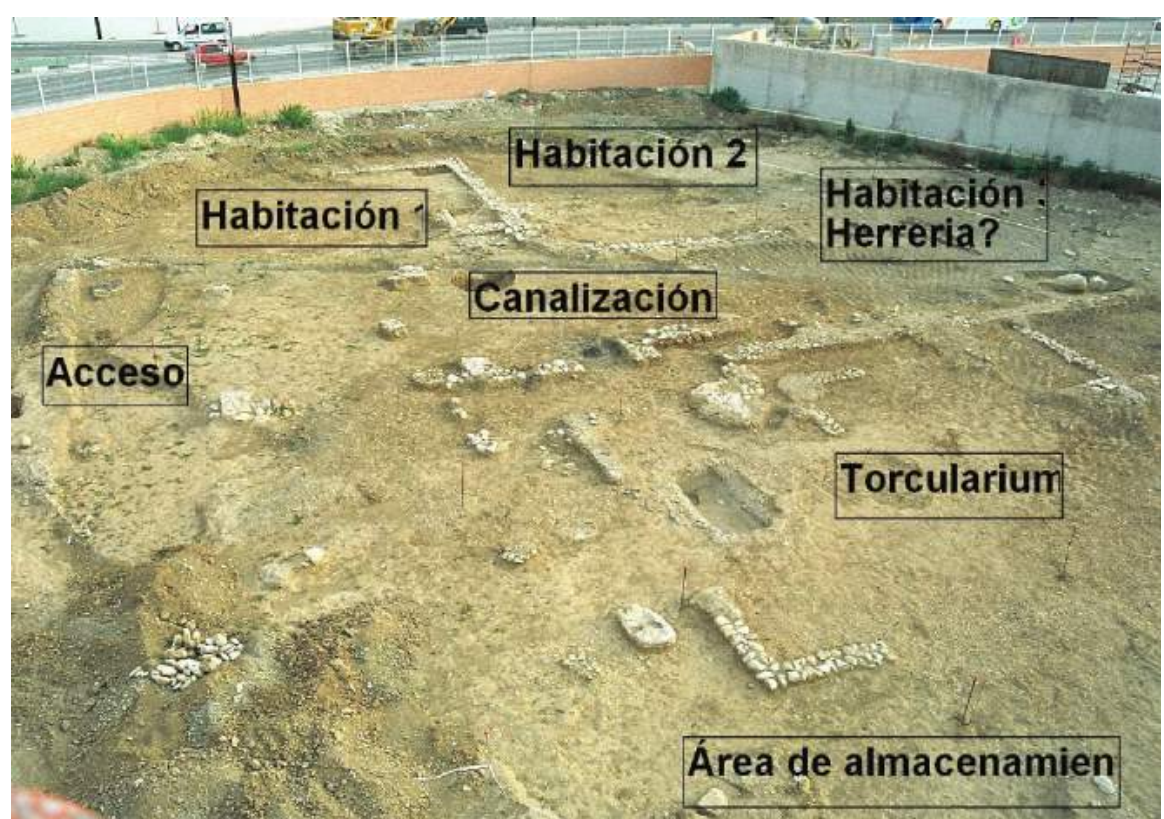

Fig. 1: Perspectiva aèria de 1'excavació. La peça es trobà en el pou situat a la vora de la canalització visible a la zona central de la part superior (Escrivà i Sifres, 2006: fig. 57).

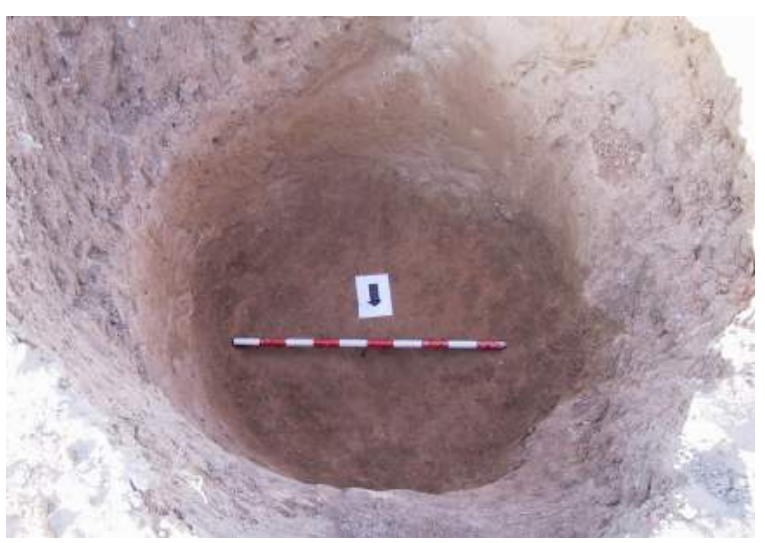

Fig. 2: Pou on es va trobar el fragment escultòric (Escrivà i Sifres, 2006: fig. 23).

avançada i té una grossària màxima de $3,7 \mathrm{~cm}$. Per darrere, la superfície presenta alguns plecs molt suaus: a la banda dreta una vora es plega de manera sinuosa formant un feix un poc inclinat cap a la dreta; la resta forma tres plecs a penes perceptibles que davallen cap a l'esquerra cada vegada més inclinats. Per davant el mantell resulta visible entre les cuixes i per darrere de l'esquerra que queda exempta per estar un poc avançada, on se'n distingeixen dos plecs verticals. En l'extrem inferior dret se'n veu un rebaixament que pot correspondre a la vora inferior que davalla cap a l'esquerra. A l'altura de la part baixa de la cuixa esquerra hi ha adossat a aquesta l'extrem superior d'un element molt incomplet que està cobert parcialment pel mantell en la part posterior; en la seua part exterior està rematat per una protuberància arrodonida, de la qual arranca un plànol de fractura que davalla fins a la cuixa. Per la part posterior es veuen diverses empremtes d'un suau cisellat inclinades cap a la dreta. Entre les cuixes, per davall de l'escrot, hi ha una ranura arrodonida de $3 \mathrm{~mm}$ d'amplària que s'estén fins que aquestes comencen a separar-se. Dues més es veuen entre el mantell i la cuixa esquerra, en la part superior quan es troben més pròxims, i en la part dreta en la línia de junta entre el mantell i la cuixa.

Una figura d'aquestes característiques fóra normal atribuir-la a algun dels tipus més frequients de Dionysos/ Bacus, com el que el representa acompanyat de la pantera (Gasparri, s. v. "Dionysos", "Bacchus" LIMC, III, 1986: 414-514, 540-566), del qual tenim un exemplar geogràficament pròxim a l'Ereta dels Moros d'Aldaia (l'Horta Sud, València), conservat al Museo Arqueológico Nacional (Balil 1988: 235-236, làm. X, núm. 199). De fet, a les províncies hispàniques les representacions d'aquesta divinitat són freqüents en la decoració escultòrica de les villae (Koppel 1995: 37-38), com veiem de manera particular al País Valencià (Arasa 2004: 233). Tanmateix, la manca d'atributs no permet la seua identificació, i la presència del mantell cobrint tota l'esquena fins a més avall de les natges no es correspon amb els tipus escultòrics més freqüients d'aquesta divinitat, que només en alguns 


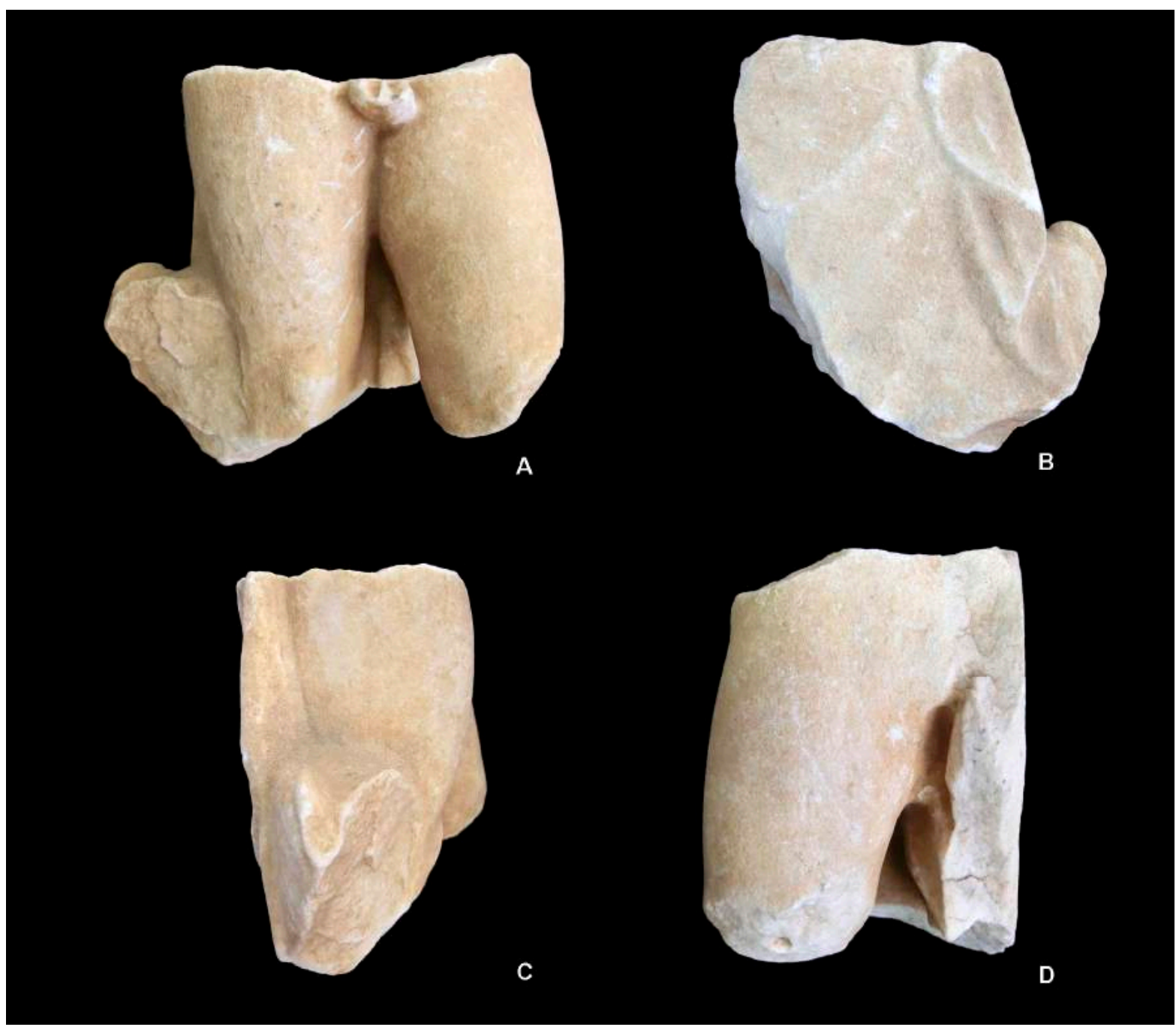

Fig. 3: Vistes frontal (A), posterior (B), dreta (C) i esquerra (D) del fragment escultòric.

casos porta l'himàtion penjant del muscle esquerre i enrotllat al braç, com en una rèplica romana d'un original hel·lenístic conservat als Museus Capitolins de Roma (Gasparri, s. v. "Dionysos, LIMC, III: 433, núm. 102). És per això que el ventall de possibilitats queda obert a les figuracions d'altres divinitats o fins i tot d'un atleta.

En les divinitats més freqüentment representades que porten mantell, com Hermes i Apol·lo, generalment aquest es disposa d'una forma diferent. La vora inclinada cap a la dreta que ací veiem no es correspon amb el drapejat més habitual, ni en el cas d'Hermes que el porta sobre el muscle esquerre, de vegades amb un extrem penjant del braç, com veiem en el tipus Richelieu (Siebert, s. v. "Hermes", LIMC, V, 1990: 367-368, núm. 946); ni en el d'Apol·lo quan porta la clàmide subjecta amb una fíbula sobre el muscle dret i creuada sobre el pit amb l'extrem també penjant del braç esquerre (Simon i Bauchhenss, s. v. "Apollo", LIMC, II, 1992: 452, núm. 556, de Virunum). Tampoc s'adiu amb el cas de les estàtues de joves amb la clàmide sobre el pit i penjant de l'esquena amb plecs completament verticals, com podem veure en el cas de Carthago Nova (Noguera 1991: 104-110, núm. 26, làm. 26); ni amb altres casos en què penja igualment del muscle esquerre i cau en diagonal per l'esquena formant un feix de plecs, com veiem en un tors de Còrdova de difícil identificació (Garriguet 2013: 389-392, fig. 6). No podem descartar, però, que es tracte d'una variant d'algun d'aquests tipus. 
Una figura com aquesta, exempta i de proporcions menors que el natural, degué formar part de la decoració de la villa, tal vegada en un espai obert com el peristil o en les termes. L'element que apareix al costat dret de la figura i li serveix de suport és possiblement un tronc, del qual resta l'extrem superior amb el que podria ser una branca. Les formes arrodonides de les cuixes pareixen correspondre a una figura jovenívola, que es representa en posició frontal i que porta un mantell que per darrere li arribava fins a la part alta de les cuixes. Les reduïdes dimensions de la part conservada -en la qual no es reconeix cap atribut- no permeten identificar amb seguretat el subjecte que representava. Per tractar-se d'una part reduïda de la figura, només pot establir-se una datació aproximada en els ss. I-II dC.

\section{BIBLIOGRAFIA}

ARASA, F. (2004): La decoración escultórica de las villae en el País Valenciano, Actas de la IV Reunión sobre Escultura Romana en Hispania (T. Nogales, L. J. Gonçalves, coord.), Madrid, 229-253.

BALIL, A. (1988): Esculturas romanas de la Península Ibérica (IX), BSAA, LIV, 223-253.

ESCRIVÀ, J. V.; SIFRES, I. (2006): Vil-la romana El Rajolar. Pars rústica. Parcel-la B2. Gandia, Valencia.

GARRIGUET, J. A. (2013): Novedades de escultura romana en Córdoba, Actas de la VII Reunión de Escultura Romana en Hispania. Homenaje al Prof. Dr. Alberto Balil (F. Acuña, R. Casal, S. González Soutelo, eds.), Santiago de Compostela, 377-402.

KOPPEL, E. M. (1995): La decoración escultórica de las villae romanas en Hispania, Poblamiento rural romano en el sureste de Hispania, Murcia, 27-48.

LIMC = Lexicon Iconographicum Mithologiae Classicae (1981 ss), Zürich-München.

MOSCARDÓ, E. (2008): El poblamiento rural romano en el territorio norte de Dianium. La comarca de la Safor-Valldigna (Valencia), Sagvntvm-PLAV 40, 177-192.

NOGUERA, J. M. (1991): La ciudad romana de Carthago Nova: la escultura, Murcia. 